\title{
The Chinese Hedgehog and the American Fox: An Invitation to Dialogue
}

Mark Saul

The fox knows many things, but the hedgehog knows one big thing.

$$
\text { -Archilochus }
$$

The title refers originally to a fragment by an obscure ancient Greek poet, made famous in an essay by Isaiah Berlin. In this essay, Berlin distinguishes two types of thinkers. Briefly, "hedgehogs" are people who concentrate their efforts on a single set of ideas, while "foxes" are those who bring a variety of ideas, from widely different areas, to bear on their work.

In Berlin's own words:

...the words can be made to yield a sense in which they mark one of the deepest differences which divide writers and thinkers, and, it may be, human beings in general. For there exists a great chasm between those, on one side, who relate everything to a single central vision, one system, less or more coherent, or articulate, in terms of which they understand, think and feel-a single, universal, organising principle in terms of which alone all that they are and say has significance-and, on the other side, those who pursue many ends, often unrelated and even contradictory, connected, if at all, only in some de facto way, for some psychological or physiological cause, related by no moral or aesthetic principle. These last lead lives, perform acts and entertain ideas that are centrifugal rather than centripetal; their thought is scattered or

Mark Saul is director of The Center for Mathematical Talent Program at Courant Institute of Mathematical Sciences, New York University. His email address is marksau1@earth1ink.net.

DOI: http://dx.doi.org/10.1090/noti1108 diffused, moving on many levels, seizing upon the essence of a vast variety of experiences and object for what they are in themselves, without, consciously or unconsciously, seeking to fit them into, or exclude them from, any one unchanging, all-embracing, sometimes self-contradictory and incomplete, at times fanatical, unitary inner vision. The first kind of intellectual and artistic personality belongs to the hedgehogs, the second to the foxes...we may, without too much fear of contradiction, say that, in this sense, Dante belongs to the first category, Shakespeare to the second; Plato, Lucretius, Pascal, Hegel, Dostoevsky, Nietzsche, Ibsen, Proust, are, in varying degrees hedgehogs; Herodotus, Aristotle, Montaigne, Erasmus, Moliere, Goethe, Pushkin, Balzac, Joyce are foxes. ${ }^{1}$

While Berlin's immediate purpose was literary criticism-he used it to examine Leo Tolstoy's ideas about history-his metaphor has influenced writers in the history of ideas in a wide range of areas.

This note applies Berlin's idea to the situation described by Liping $\mathrm{Ma}^{2}$ with regard to Americanstyle and Chinese-style elementary mathematics curriculum documents. Ma argues that the very structure of American curricula, as laid out in these documents, leads to flaws in the system of education. But, seen through the lens of Berlin, one

\footnotetext{
${ }^{1}$ Isaiah Berlin, The Hedgehog and the Fox. An Essay on Tolstoy's View of History. Elephant Paperbacks, Ivan R. Dee, Publisher, Chicago, 1993. Originally published 1953 by George Weidenfeld and Nicolson, Ltd. No place of publication listed, pages 3-4.

${ }^{2}$ Liping Ma, "A critique of the structure of U.S. elementary school mathematics", Notices of the American Mathematical Society, Vol. 60, No. 10, Nov. 2013, pp. 1282-1296.
} 
can say that there are corresponding flaws in the Chinese system. And, I argue, a synthesis of the positive aspects of both will achieve more than either of us has achieved separately.

For what follows, it is important to note that Berlin-and most other writers - do not see any value judgment in the division into hedgehogs and foxes. Berlin himself (above) names important hedgehogs and foxes, and it would be difficult to say that one set of these thinkers is in any way better or more important than the other. The same list shows that Berlin's classification does not correlate with the field in which the thinker is working. Any field can profit from either sort of contribution.

From Berlin's point of view, we can characterize the Chinese curricula described by Ma as largely hedgehog-like, while American thinking is much more fox-like. If, like Berlin, we withdraw from the notion of judgment, we can distinguish strong and weak points in either way of thinking. And, if we look for ways to synthesize these viewpoints, we may be able to strengthen both efforts.

Before commenting on this possibility, I note that the criterion of "coherence" used by Ma to judge curricula is a problematic one. For example, we could construct a marvelously coherent curriculum centered around the goal of learning the English names of rational numbers between, say, $10^{-24}$ and $10^{24}$. Children would be taught to recite these numbers correctly, complete with Latin or Greek prefixes, and using the word "and" in the correct places. The skill would be easily demonstrable, both on a written test and at the dinner table. And, in the age of teraflops and nanoseconds, a case could be made that it is useful. But central?

Less flippantly, we might construct another marvelously coherent curriculum around mastery of a certain set of arithmetic algorithms, termed "standard". (Whether or not this term is appropriate is here irrelevant.) Students would learn to multiply three-digit numbers fluently and accurately, would perform long division in an approved format, and would subtract the bottom number from the top, using algorithms tailor-made and honed by historical forces for computation in the base ten system, itself a product of long intellectual evolution.

These skills would be easily demonstrable on a written test, if not at the dinner table. Are they useful, in this age of ubiquitous hand-held calculators? We can debate that question at another time. The point here is that the answer to that question does not depend on the coherence of the curriculum, but on values external to the curriculum. Values are cultural, not mathematical. Values, like taste or morality, are not subject to proof (the central criterion of mathematics) or refutation (the central criterion of science). So whether or not a curriculum is useful is not a question answered by looking at internal coherence.

\section{The Structure of American Curricula: Where Is the Center?}

Let us set aside these comments for a moment, and accept the notion of coherence as central to the discussion of a curriculum. It is my view that Ma's note makes the hedgehog-like assumption that arithmetic is central to elementary mathematics, then demonstrates the coherence of the Chinese curriculum she discusses. But if another assumption is made about the central concept for a curriculum, then the coherence may vanish, or may reduce to a foolish consistency. I will argue below that Ma's comments flirt with this danger.

To illustrate why I question the assumption of the centrality of arithmetic in elementary education, let us consider some third-grade students. (These sketches are in fact drawn from life.) Student A can add two-digit numbers in the standard way: $46+35=81$. She can do this consistently, accurately, and fluently, and can do the same for three- and four-digit numbers. Student B understands what addition means, but has trouble remembering to "carry the one", or makes similar errors in computation. So he may write: $46+35=71$. Student $C$ has his own idiosyncratic way of adding two two-digit numbers (for example, he might reason that $47+47$ is six less than 100 because 50 $+50=100$, and so on). Perhaps it is not as efficient as student A's. And perhaps it doesn't quite generalize to three-digit numbers. But it serves him for many two-digit numbers, and he clearly knows what he's doing, having invented the algorithm.

On the other hand, student A makes mistakes like adding 46 degrees in New York to 35 degrees in Chicago, getting 81 degrees, which student B does not make. Or student A says that the perimeter of a rectangle with adjacent sides of lengths 46 and 35 is 81 , while student $B$, says it is 142 (recalling his error in the last paragraph). That is, student A makes errors in logic while student B makes errors in computation. And student $C$ makes errors in neither, but has to re-think the problem when he must add three-digit numbers with paper and pencil.

The assumption we make here is that the errors made by student A are much more significant than those made by student B or C. The empirical evidence for making this assumption, drawn from my own classroom experience and that of colleagues, is that the errors of student $\mathrm{B}$ or $\mathrm{C}$ are much more easily remediated than those of student A.

It follows from this assumption that the central goal of elementary mathematics education-and perhaps of secondary mathematics education-is an understanding of logic (not formal or symbolic logic, but the intuitive and essential idea of a chain of implications). The study of arithmetic algorithms, when well taught, then becomes a tool for the delivery of what I see as a deeper skill: reasoning from one statement to another, a skill 
that cannot be duplicated, or even aided, by the use of a calculator.

\section{An Alternative View of American Curricula}

Using the alternative assumption of the centrality of logic in elementary curriculum, we can reexamine some of Ma's points.

Most of Ma's discussion is an examination of syllabi, and standards documents, rather than about live classrooms. The hedgehog-like assumption is made right at the start of the discussion, in noting that older American textbooks of arithmetic took Euclid's Elements as the standard for a unified exposition of their subject, and that more recently, Chinese texts, among others, have continued and refined this tradition.

But it is clear, from this very choice of models, that there is something deeper than simply arithmetic which is the standard. Euclid, too, was in some ways a hedgehog-like thinker. He has a wonderfully articulated paradigm of mathematical truth, using geometry as the central topic. His rigorous treatment of arithmetic (including the arithmetic of irrational numbers) and number theory was based more or less entirely on geometric intuition, as was his treatise on optics that has come down to us ${ }^{3}$ (but not as part of the Elements). His algebra remained two-or three-dimensional because it, too, is expressed geometrically. The solution of equations of higher degree, and an efficient algebraic notation, were never developed by the Greeks.

The fact that one can base a development of arithmetic on the same methods Euclid used for geometry suggests that Euclid's basic concept is deeper. It consists in the idea of an axiomatic system, or the underlying concept of implication: one statement or set of statements implying others. If we take this wider view of what Euclid is about, indeed of what mathematics is about, Ma's analysis looks somewhat different.

The Chinese, as described by Ma, can be now seen as using an exposition of arithmetic as an example of an axiomatic system. On the pedagogical level, the Chinese elementary curriculum uses statements from arithmetic to build a notion of implication. A student who knows the "compensation law for addition" that Ma mentions ${ }^{4}$ can reason that if $8+8=16$, then $9+7$ must also equal 16 . That if, well taught, the Chinese curriculum delivers not simply the facts and algorithms of arithmetic, but also ways to reason about numbers and statements about numbers. Poorly taught, of course, it deteriorates into recitation and memorization.

\footnotetext{
${ }^{3}$ See http://www math corne]ledu/ web1600/ Terre11_0ptics0fEuclid.pdf (accessed September 2013).

${ }^{4} \mathrm{Ma}$, Op. cit., page 1286 .
}

Likewise, the American curriculum-as described by Ma-can now be seen differently. Placing implication at the center of elementary mathematics, we can read American curricula and standards as delivering this same central concept, but using a variety of examples: arithmetic, geometric, statistical, probabilistic, and so on. Viewed this way, the American "strand" structure pointed out by Ma becomes a flexible asset, and not a wild liability.

Has this asset been exploited in published American curricula? I would argue that the answer is "sometimes". But I would likewise argue that the Chinese curriculum "sometimes" uses arithmetic to deliver more profound mathematical ideas. Evidence for this is lacking in Ma's work (she concentrates, here and elsewhere, on successful instances of Chinese teaching, and in fact those are probably the ones we can learn the most from). My own work in China with gifted students indicates otherwise: that they are often poised to think out of the box, but must be invited. That is, I have found that when Chinese students are faced with new and unusual problems, they often balk, intellectually. They try to think where they have seen the problem before. Sometimes they apply familiar techniques or patterns of solution inappropriately. However (my work is almost entirely with gifted students), when invited to invent their own solutions, they respond quickly, and often succeed brilliantly. The point is not that they cannot think outside the box. The point is that their curriculum does not invite this. Rather, it cultivates a deep and reliable mastery of a specific set of techniques.

Chinese colleagues have commented on this phenomenon. One said, "I don't worry about my [Chinese] students passing a test. But I want to give them opportunities to do something new." I have often been asked, by Chinese colleagues, "How can I introduce creativity into my classroom?" This is itself a hedgehog-like question, as if there were an algorithm for inducing creativity. Colleagues I've worked with in China have often questioned exactly the highly structured curriculum that Ma describes. Perhaps the most striking comment on this level is about Chinese Nobel prize winners in the sciences. A list of these will show that none of them did their work in Chinese institutions. ${ }^{5}$ Some might see this as a narrow comment on graduate education and research institutions, but the implication that many Chinese educators draw is that they need to look at how the twig is bent.

I might add that I have found this phenomenon in work with American students as well. They too,

\footnotetext{
${ }^{5}$ See http://en.wikipedia.org/wiki/List_of_ Chinese_Nobe1_1aureates, accessed September 2013. One laureate is listed as affiliated with the University of Hong Kong. All the others worked in American or European institutions. Two winners in peace and literature were educated in China.
} 
often need to be invited to think outside the box that their curriculum has put them in. This is partly a consequence of the very nature of curriculum: a set of skills and concepts to be mastered. The striking aspects of my work with Chinese (and Japanese, and Taiwanese, and Malaysian) students are two: the occurrence of the phenomenon in very able students, and the alacrity with which they accept the invitation to break outside the box created by their training.

Ma brings up another point in her work, one not directly connected to her central thesis. We can look at curriculum in yet another way (examine yet another strand!): the way in which it is perceived by the student. This aspect of curriculum is not discussed by Ma. It is perhaps the most fox-like way of looking at education, in that it has, as of now, the least structure. As Ma points out, the structure of mathematics has been worked out over thousands of years. On the other hand, we are just beginning to formulate and test theories of learning, either of mathematics or of other subjects. And we have almost no theories of teaching, which cannot be directly inferred either from theories of learning or from the structure of mathematics.

Ma mentions the fact that many of the American curriculum documents she reviews include strands that are not properly mathematics, involving attitudes towards mathematics, "number sense", or problem solving. Should these in fact be part of a curriculum document? This is a difficult judgment call. The question becomes: is teaching and learning mathematics informed solely, or even centrally, by the nature of mathematics itself? I do not wish to answer, or assume an answer to, this question here-it is much too involved. But I would argue that a fox-like way of thinking about curriculum would include at least a consideration of these other factors, even if merely to reject them or distinguish them from mathematics "proper".

\section{The Critique}

Ma's article goes beyond a description and characterization of specific curriculum documents. She levels three charges against the "strand" structure of the American curriculum: instability, lack of accumulation of knowledge (of teaching and learning), and incoherence among concepts. In this next section-the least constructive in this essayargue that (a) many of these charges vanish if we look at curriculum as logic-centered, rather than arithmetic-centered, and (b) many of these same negative characteristics can be found in the "core structured" arithmetic-centered curriculum, as Ma describes it. We look at these charges one by one.

\section{Instability}

Ma asserts that the "strands structure" leads to instability in the curriculum. From the fox's point of view, we might just as well say that it leads to flexibility(!). As we find new ways to approach the basic logical structure of mathematics, a "strands structure" will allow us to incorporate these new approaches easily into classroom technique. For example, the American curriculum has looked at probability, statistics, and computer algorithms to find ways to approach the idea of implication.

It is important to understand that we are talking here about Ma's concept of structure, and not about implementation of structure. Perhaps this or that American curriculum has not been successful in flexibly introducing new ideas, or has introduced them inaccurately. The argument against "strands", against fox-like thinking, would have to be that it actually implies failure in introducing new ideas. But the argument against the Chinese curriculum could equally be made that it prevents-not just makes difficult-the introduction of new approaches. The American structure has doors, where the Chinese structure-as described by Ma-has walls.

\section{Accumulation of Knowledge}

In fact, American curriculum writers do accumulate knowledge. We now know better than we did thirty years ago how to teach combinatorics in elementary school. We have had a number of successes in introducing concepts from computer science into elementary education. Is this mathematics? Do these topics relate to the drawing of logical inferences? I would argue that the relationships are certainly there, but are still being worked out. That is, knowledge is still being accumulated.

And, I would argue, the multi-strand nature of American curriculum encourages the accumulation of knowledge. A more open structure to curriculum allows us to introduce new materials in ways that are consistent with the old. Whether a student draws implications from a statement in arithmetic, in geometry, in statistics, or whether they use arithmetic equations or a computer programming language, becomes a detail of implementation, rather than a source of confusion.

\section{Incoherence}

We can say the same about what Ma terms "incoherence". No matter how we structure our curriculum, we need teachers who are trained to see how mathematics coheres. A narrow focus on arithmetic may easily lead to an incoherent view among teachers. Ma herself mentions that only $10 \%$ of her sample of Chinese teachers really had a profound understanding of arithmetic. ${ }^{6}$ This statistic seems to indicate that concentrating on arithmetic leads to an incoherent view of mathematics for most of the teachers exposed to it.

Incoherence in a single-strand curriculum can occur on the student level as well. We have mentioned

$\overline{{ }^{6} \mathrm{Ma} \text {, Op. cit., page } 1295 .}$ 
that a well-taught arithmetic-centered curriculum may be capable of delivering the concepts of implication and logic. (Whether this transfer is easy or difficult to implement is an empirical question, not examined by Ma.) But let us take a case where a student has successfully learned about logic from a study of arithmetic. Such a student may or may not see that its application to counting problems is part of mathematics. Or that we can harness the same sort of logic to a study of geometry. That is, a narrow focus on arithmetic can create a discontinuity in the student's experience, just the fault that Ma attributes to a "strand" structure of curriculum.

\section{Implementation and Synthesis}

Ma's central point, as I read it, is that a strand structure of American curriculum, whatever its strengths, encourages poor implementation. I see an equal but opposite danger with a corestructured curriculum. Especially in America, with our emphasis on testing and accountability, the temptation will be strong to teach students the mechanics of arithmetic without its meaning. And this is certainly possible. There is no evidence that a mastery of standard algorithms or of the notion of place value delivers to students power in logical deduction, any more than there is evidence that strong deductive powers allow students fluency in arithmetic. A faulty delivery of either style of curriculum will not serve students well, and there is no "teacher-proof" way of designing a curriculum.

And here is where the notion of a synthesis becomes useful. My feeling is that we must look at both types of thinkers, hedgehogs and foxes, and find ways to use both. For example, we can find foxes to design curricula with many strands, then hedgehogs to polish each strand. A conscious effort to fit them together would effect a synthesis of the two views.

Ma herself points out that many Chinese are open to working this way: they are looking at American curricula to see what they might learn. Where Ma bemoans this phenomenon, I celebrate it. Reciprocally, the success of her book Knowing and Teaching Elementary Mathematics is one indication that some of us are also open to new insights. Let us hope that this sort of synthesis can be accomplished successfully.

I would like to thank Susan Addington, Judy Roitman, Douglas Clements, Yvonne Lai, and Peter Shiue for their input into this article.

\section{Marc Yor (1949-2014)}

\section{Jean-François Le Gall and Jim Pitman}

Marc Yor, one of the most distinguished probabilists in the world in recent decades, died suddenly on January 9, 2014, near his home in St. Chéron, France, at the age of sixty-four. He was born on July 24, 1949, in Brétigny-sur-Orge, France. After studying at the École normale supérieure de Cachan, with thesis work under the supervision of Pierre Priouret, he quickly became a researcher at the French Centre National de la Recherche Scientifique (CNRS), then in 1981 a professor at the

Jean-François Le Gall is professor of mathematics at the Université Paris-Sud Orsay. His email address is jeanfrancois.1ega11@math.u-psud.fr.

Jim Pitman is is professor of statistics at the University of California, Berkeley. His email address is pitman@stat. berke1ey. edu.

First appeared in the IMS Bulletin, February 15, 2014 (http://bu11etin.imstat.org/2014/02/marc-yor1949\%E2\%80\%9320147. Article by Jean-François Le Gall and Jim Pitman, with thanks to Jean Bertoin for his advice.

DOI: http://dx.doi.org/10.1090/noti1128
Université Pierre et Marie Curie, where he remained until his retirement on January 1, 2014.

Marc Yor is world renowned as a prolific researcher in the theory of probability and stochastic processes. He wrote over 400 research articles and ten research monographs. Most of the research articles and several of the monographs were written jointly with one or more coauthors from a list of over 100 collaborators from all over the world (see http://zbmath. org/authors/?q=ai:yor.marc including many of the most prominent probabilists of the era. During the 1980s and 1990s, Marc Yor largely took over from Paul-André Meyer the mantle of responsibility for development of research in probability in France. He was an influential editor of the Séminaire de Probabilités, founded by Meyer in 1967, over a span of twenty five years. In this capacity he set a new tone for the Séminaire as a diverse compendium of contemporary research in probability, with a focus on work done in France, but also welcoming contributions from abroad. 